\title{
Reversal of Long-Term Potentiation-Like Plasticity Processes after Motor Learning Disrupts Skill Retention
}

\author{
Gabriela Cantarero, ${ }^{1}$ Ashley Lloyd, ${ }^{2}$ and Pablo Celnik ${ }^{1,2,3}$ \\ ${ }^{1}$ Department of Neuroscience, School of Medicine, Johns Hopkins University, Baltimore, Maryland 21205, and Departments of ${ }^{2}$ Physical Medicine and \\ Rehabilitation and ${ }^{3}$ Neurology, Johns Hopkins Medical Institution, Baltimore, Maryland 21287
}

\begin{abstract}
Plasticity of synaptic connections in the primary motor cortex (M1) is thought to play an essential role in learning and memory. Human and animal studies have shown that motor learning results in long-term potentiation (LTP)-like plasticity processes, namely potentiation of M1 and a temporary occlusion of additional LTP-like plasticity. Moreover, biochemical processes essential for LTP are also crucial for certain types of motor learning and memory. Thus, it has been speculated that the occlusion of LTP-like plasticity after learning, indicative of how much LTP was used to learn, is essential for retention. Here we provide supporting evidence of it in humans. Induction of LTP-like plasticity can be abolished using a depotentiation protocol (DePo) consisting of brief continuous theta burst stimulation. We used transcranial magnetic stimulation to assess whether application of DePo over M1 after motor learning affected (1) occlusion of LTP-like plasticity and (2) retention of motor skill learning. We found that the magnitude of motor memory retention is proportional to the magnitude of occlusion of LTP-like plasticity. Moreover, DePo stimulation over M1, but not over a control site, reversed the occlusion of LTP-like plasticity induced by motor learning and disrupted skill retention relative to control subjects. Altogether, these results provide evidence of a link between occlusion of LTP-like plasticity and retention and that this measure could be used as a biomarker to predict retention. Importantly, attempts to reverse the occlusion of LTP-like plasticity after motor learning comes with the cost of reducing retention of motor learning.
\end{abstract}

\section{Introduction}

Changes in the plasticity of synaptic connections are widely believed to play an essential role in learning and memory (Martin et al., 2000). When rats are trained on a motor skill, the evoked potentials elicited from the involved primary motor cortex (M1) are larger (Rioult-Pedotti et al., 1998; Monfils and Teskey, 2004; Hodgson et al., 2005). Interestingly, motor learning temporarily occludes artificially induced long-term potentiation (LTP) and increases induction of long-term depression (LTD) (RioultPedotti et al., 1998, 2000, 2007). Although occlusion of LTP after motor learning indicates that M1 engages LTP mechanisms to strengthen synapses, the behavioral correlate of this physiological observation is not completely known.

Evidence suggests that M1 plays a vital role in retention, i.e., the process by which acquisition of skilled motor performance can be translated into long-lasting behavioral changes (Nudo et al., 1996; Kleim et al., 1998, 2002, 2003; Sanes and Donoghue, 2000; Remple et al., 2001; Muellbacher et al., 2002; Conner et al., 2003; Hadipour-Niktarash et al., 2007; Reis et al., 2009; Galea et

Received April 2, 2013; revised June 25, 2013; accepted June 29, 2013.

Author contributions: G.C. and P.C. designed research; G.C. performed research; G.C. and A.L. analyzed data; G.C. and P.C. wrote the paper.

This work was supported by National Institutes of Health/National Institute of Child Health and Development Grants R01HD053793 and R01HD073147, the Brain Science Institute of Johns Hopkins University, and National Institute of Neurological Disorders and Stroke Grant 1F31NS073386-01A1.

Correspondence should be addressed to Pablo Celnik, Department of Physical Medicine and Rehabilitation, Johns Hopkins Medical Institution, 707 North Broadway, Baltimore, MD 21231. E-mail: pcelnik@jhmi.edu.

DOI:10.1523/JNEUROSCI.1399-13.2013

Copyright $\odot 2013$ the authors $\quad 0270-6474 / 13 / 3312862-08 \$ 15.00 / 0$ al., 2011). Similar to animal studies, work in humans has shown that motor learning potentiates corticospinal excitability (Liepert et al., 1998; Muellbacher et al., 2001; Perez et al., 2004; Ziemann et al., 2004; Rosenkranz et al., 2007) and results in a temporary occlusion of induction of LTP-like plasticity (Ziemann et al., 2004; Stefan et al., 2006; Rosenkranz et al., 2007; Cantarero et al., 2013). Of note, the temporary occlusion of LTP-like plasticity coincides with a temporary period of instability after motor learning during which motor memories are susceptible to interference by either disruptive stimulation (Muellbacher et al., 2002; Robertson et al., 2004, 2005; Cothros et al., 2006; Richardson et al., 2006; Hadipour-Niktarash et al., 2007; Korman et al., 2007) or subsequent training on a similar motor task (Brashers-Krug et al., 1996; Shadmehr et al., 1997; Bock et al., 2001; Goedert et al., 2002; Wigmore et al., 2002; Walker et al., 2003; Robertson et al., 2004; Krakauer et al., 2005; Krakauer and Shadmehr 2006; Ghilardi et al., 2009; Criscimagna-Hemminger et al., 2008; Cantarero et al., 2013). These properties suggest a link between occlusion of LTP processes and retention of motor memories. Therefore, in this study, we hypothesized that, if LTP-like changes leading to occlusion after skill motor learning are essential for retention, then artificially reversing occlusion immediately after training should interfere with skill retention.

Previously, it has been shown that, in animals and humans, it is possible to reverse LTP/LTP-like effects with depotentiation stimulation protocols (DePo) (Lee et al., 2000; Huang et al., 2010). In humans, this consists of short bursts of transcranial magnetic stimulation (TMS) that on their own have no clear effect on cortical excitability (Huang et al., 2010). To assess the 
Table 1. Gender, age, and handedness information for all subjects

\begin{tabular}{llllll}
\hline Parameters & DeP0-M1 & DeP0-FZ & DeP0-M1-N0tDCS & No TBS & ANOVA \\
\hline Gender & 5 females, 5 males & 7 females, 3 males & 4 females, 6 males & 7 females, 6 males \\
Age & $24.0 \pm 1.4$ & $26.2 \pm 2.1$ & $24.2 \pm 1.0$ & $24.8 \pm 0.9$ & NS \\
Handedness & 10 right, 0 left & 9 right, 1 left & 9 right, 1 left & NS \\
\hline
\end{tabular}

All groups were similar across gender, age, and handedness. Data are means \pm SEM.

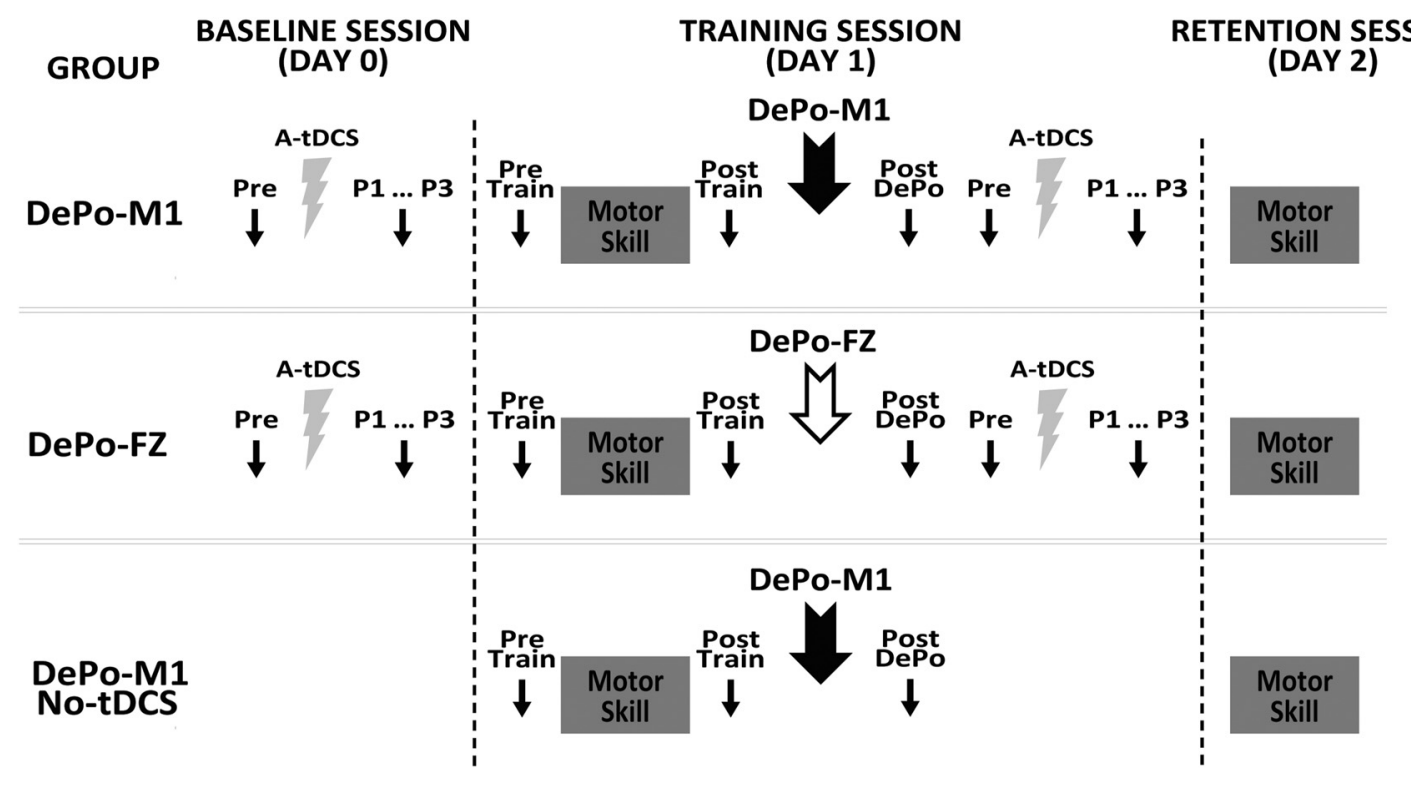

Figure 1. Experimental protocol for all groups. Subjects in group DeP0-M1 ( $n=10)$ participated in three separate sessions: baseline, training, and retention sessions. In the baseline session (D0), subjects sat at rest and underwent 5 min of AtDCS applied over M1 (gray ray) to assess their capacity for AtDCS-induced potentiating aftereffects. MEP amplitudes (black arrows) were assessed before AtDCS application and again immediately [Post1 (P1)], 2 min (P2), and $4 \mathrm{~min}$ (P3) after AtDCS application. In the training session (D1), subjects trained four epochs of 30 trials (120 trials) of the SVIPT. After motor training, DePo was applied over M1. To assess changes in corticomotor excitability as a function of training and DePo, MEP amplitudes were measured Pre-MT, Post-MT, and again Post-DePo. Finally, after application of DeP0, 5 min of AtDCS was again applied over M1, followed by post-AtDCS aftereffects assessment at $0-4$ min as done in D0. Subjects returned the following day for the retention session (D2) and trained 120 trials of the SVIPT. Subjects in group DePo-FZ ( $n=10)$ were identical to group DePo-M1 except that DePo was applied over the control site, FZ. Group DeP0-M1-NOtDCS $(n=10)$ was identical to group DeP0-M1, except that no tDCS was applied and no TMS measurements were made in conjunction with tDCS.

relationship between occlusion and retention, we applied DePo over M1 immediately after motor training to reverse motor learning-induced LTP-like plasticity and measured its effects on skill performance the following day (retention session).

\section{Materials and Methods}

Subjects. The study was approved by the Johns Hopkins School of Medicine Institutional Review Board in accordance to the Declaration of Helsinki, and written informed consent was obtained from all participants. The experiment was performed on 31 healthy subjects ( 14 men, 17 women, ranging from 18 to 39 years old) with no history of neurological or psychiatric disorders. There were no significant differences in age, gender, and handedness across groups (Table 1).

Experimental procedures. All subjects in the different groups trained the identical amount of the sequential visuomotor isometric pinch task (SVIPT) in which squeezing an isometric force transducer moves a computer cursor into a set of small windows (Reis et al. 2009, Cantarero et al. 2013). In the training session [day 1 (D1)], subjects trained 120 trials (four epochs of 30 trials) of the SVIPT and then received DePo after training. The following day in the retention session [day 2 (D2)], participants returned for a retention test of the SVIPT (four epochs of 30 trials). In addition to motor training, each subject underwent two physiological measurements: (1) assessing changes in corticospinal excitability and (2) assessing changes in LTP-like capacity (i.e., occlusion) as a function of motor training and DePo. To assess changes in corticospinal excitability, we compared motor-evoked potential (MEP) amplitude before motor training (pre-MT), immediately after motor training (post-MT), and immediately after DePo (Post-DePo) (Fig. 1). To assess capacity to undergo LTP-like changes, we recorded MEP amplitudes before and imme- diately after application of anodal transcranial direct current stimulation (AtDCS) on a day when subjects were at rest the entire session [day 0 (D0), baseline session], as well as before and after application of AtDCS after subjects had engaged in the motor training task and after application of DePo (D1, training session). The difference in magnitude of AtDCS-elicited aftereffects across days (D0-D1) was the occlusion index (OI).

To assess the relationship between occlusion and retention, subjects were randomly divided in two main groups. In the training session (D1), group DePo-M1 $(n=10)$ received DePo over M1 after motor training, whereas subjects in the DePo-FZ group $(n=10)$ received DePo over control site FZ.

To determine whether AtDCS applied after training influenced behavior, we recruited an additional control group, DePo-M1-NOtDCS $(n=$ 10) in which subjects trained identically to group DePo-M1, but no tDCS was applied and no TMS measurements were made in conjunction with tDCS (Fig. 1).

Finally, to ensure that DePo effects over FZ did not affect motor behavior, we performed an additional comparison using data from a previously published group (Cantarero et al., 2013). Group No DePo ( $n=11$; AA group from the study by Cantarero et al., 2013) performed the same training and received AtDCS as the DePo-FZ group except that no DePo was applied.

Skill task: SVIPT. As done by Reis et al. (2009) and Cantarero et al. (2013), subjects were seated in front of a computer monitor and held an isometric force transducer between the thumb and index finger of the dominant hand. Pinching the force transducer controlled the movement of an on-screen cursor. Participants were instructed to navigate the cursor as quickly and accurately as possible between a HOME position and 
five gates by alternating the pinch force exerted onto the transducer. The sequence is HOME-1-HOME-2-HOME-3-HOME-4-HOME-5. We defined the movement time per trial as movement onset to reaching gate 5 . We calculated the error rate as the proportion of trials with at least one overshooting or undershooting movement per epoch (epoch is the average across 30 consecutive trials).

To quantify motor learning, we determined changes in the speedaccuracy tradeoff function (SAF). The proposed estimate of changes in the SAF is the skill measure, $a$ :

$$
a=\frac{1-\text { error rate }}{\text { error rate }\left(\ln (\text { movement time })^{b}\right)}
$$

where error rate and movement time are averages over 30 trials, and the value of $b$ is 5.424 (Reis et al., 2009).

To measure performance of the motor skill, we quantified online and offline effects, D2 performance, and D2 relative to D1 performance (D2D1), defined as follows:

Online effects

$$
=\text { skill measure }_{\text {Dayl, last epoch }}-\text { skill measure }_{\text {Dayl, first epoch }} \text {, }
$$

Offline effects

$$
=\text { skill measure }_{\text {Day2, first epoch }}-\text { skill measure }_{\text {Day1, last epoch }},
$$

D2-D1 performance

$$
=\operatorname{mean}\left(\text { skill measure }_{\text {Day2 }}\right)-\text { mean }\left(\text { skill measure }_{\text {Day1 }}\right) .
$$

TMS and recording. Focal TMS was performed using a flat figure-eightshaped magnetic coil connected to a Magstim Rapid ${ }^{2}$ stimulator (Magstim). The coil was held tangentially to the skull with the handle pointing backward and laterally at a $45^{\circ}$ angle to the sagittal plane.

Electromyographic (EMG) activity was recorded using disposable surface electrodes placed over the first dorsal interosseous (FDI) muscle of the dominant hand. Signals were sampled at $2 \mathrm{kHz}$, visually displayed online, and analyzed offline using MATLAB (MathWorks).

Corticospinal excitability measures. Using a frameless neuronavigation system (BrainSight; Rogue Research), we coregistered the subjects' heads to a standard magnetic resonance image. We then identified and marked as the "hotspot" the optimal M1 area for eliciting MEPs in the resting FDI muscle. In this location, we determined the resting motor threshold (rMT) as the minimum TMS intensity that evoked an MEP of $50 \mu \mathrm{V}$ in at least 5 of 10 trials in the resting FDI muscle (Rossini et al., 1994). Muscle relaxation was monitored by visual feedback of the EMG recording.

To assess corticospinal excitability, we determined the stimulus intensity needed to evoke an MEP with peak-to-peak amplitude of $\sim 1 \mathrm{mV}$ [stimulus intensity $1 \mathrm{mV}(\mathrm{S} 1 \mathrm{mV})$ ]. Ten MEPs were recorded for each $\mathrm{S} 1 \mathrm{mV}$ intensity measurement. MEP measures took $\sim 1 \mathrm{~min}$ to complete.

DePo. The protocol used for depotentiation was based on those that were reported previously in humans (Huang et al., 2010, 2011). Depotentiation comprised a shorter form of continuous TBS containing 150 pulses (cTBS150) lasting $10 \mathrm{~s}$. Importantly, in humans, cTBS150 was designed to reverse potentiating plasticity but, when applied at rest, has no effect on cortical excitability (Huang et al., 2010). This is consistent with animal studies in which depotentiation is normally induced by a protocol milder than those used to induce LTD but on its own has no effect on a resting cortex (Zhou and Poo, 2004). Therefore, stimulation consisted of bursts of three pulses at $50 \mathrm{~Hz}$ repeated at $200 \mathrm{~ms}$ intervals (i.e., at $5 \mathrm{~Hz}$ ), given over the motor hotspot or over a control site at an intensity of $70 \%$ of the rMT. Based on previous studies (Cohen et al., 1997; Block et al., 2013), we chose FZ as a control site, which was determined using the 10-20 electroencephalogram coordinate system (Lagerlund et al., 1993).

Transcranial direct current stimulation. As done previously, we applied AtDCS to assess the capacity of M1 to undergo LTP-like plasticity at rest and after motor training/depotentiation (Cantarero et al., 2013). We chose this because AtDCS aftereffects have been stable and consistent across human subjects and are easily tolerated. AtDCS was delivered via two conducting $25 \mathrm{~cm}^{2}$ electrodes covered with saline-soaked sponges. Using a Phoresor II Auto device (model PM850; IOMED), we implemented a bipolar electrode montage (contralateral M1 and ipsilateral supraorbital area). In this manner, we applied AtDCS for 5 min over the corticospinal hand representation of the FDI muscle, as identified by TMS, at an intensity of $1 \mathrm{~mA}$. This form of stimulation has been shown to increase cortical excitability through NMDA receptors, GABA, BDNF, and calcium-dependent mechanisms in humans and animals (Islam et al., 1995; Liebetanz et al., 2002; Nitsche et al., 2003; Stagg et al., 2009; Fritsch et al., 2010) and induce LTP in mice slice preparations (Fritsch et al., 2010; Ranieri et al., 2012).

Quantification of LTP-like plasticity. This measurement was described previously by Cantarero et al. (2013). To assess the baseline effect of AtDCS on cortical excitability, S1mV was used to record MEP amplitudes before and after application of 5 min of AtDCS on a separate day, when subjects were at rest the entire session (D0). To assess the duration of the AtDCS aftereffects, S1mV was repeated immediately, 2 min, and 4 min after application of AtDCS (Fig. 1). For each subject the average of 10 MEP amplitudes for each time point was calculated. Changes in MEP amplitudes were expressed as a ratio of the MEP amplitude at post-time points relative to the pre-AtDCS MEP amplitude. On D1 after training, we performed identical measurements of MEP amplitudes before and after application of AtDCS.

To quantify the magnitude of occlusion of LTP-like plasticity, we calculated the OI for each subject. The peak mean MEP amplitude after application of AtDCS was normalized to the MEP amplitude before AtDCS for each individual subject. This measurement was done for both D0 and D1:

$$
\mathrm{OI}=\mathrm{DO}\left[\frac{\text { Post-MEP }}{\text { Pre-MEP }}\right]-\mathrm{D} 1\left[\frac{\text { Post-MEP }}{\text { Pre-MEP }}\right]
$$

This measurement serves as an indirect index of how much LTP-like plasticity was used during training, in which larger values for the OI are indicative of more occlusion.

Data analyses. We used separate polynomial nested repeated-measures ANOVA $\left(\mathrm{ANOVA}_{\mathrm{RM}}\right.$ ) for the different measures. Post hoc analysis was done with two-tailed $t$ tests when appropriate correcting for multiple comparisons when necessary.

The primary outcome measure for corticospinal excitability was the peak-to-peak MEP amplitudes. The amount of corticospinal excitability changes attributable to training and or DePo was compared using ANOVA $_{\mathrm{RM}}$ with factors group (DePo-M1, DePo-FZ, DePo-M1NOtDCS) as the between factor and time (Pre-MT, Post-MT, Post-DePo) as within factors. To understand the effects of depotentiation on corticomotor excitability after training, we subtracted the Post-DePo from the Post-MT MEP amplitude within subjects. These deltas were compared across groups (DePo-M1, DePo-FZ, DePo-M1-NOtDCS) with an ANOVA and a subsequent independent $t$ test.

The amount of potentiation plasticity aftereffects after AtDCS was compared using ANOVA $_{\mathrm{RM}}$ with the between factor group (DePo-M1, DePo-FZ) and the within factors day (D0, D1) and time (Pre-AtDCS and mean of 0, 2, 4 min post-AtDCS).

The primary behavioral outcome measure was the skill measure. Differences in performance of the motor skill were compared using ANOVA $_{\mathrm{RM}}$ with group (DePo-M1, DePo-FZ, DePo-M1-NOtDCS) as the between factor and day (D1, D2) and epoch (Epoch1, Epoch2, Epoch3, Epoch4) as within factors. We performed a subsequent analysis comparing the

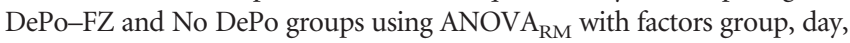
and epoch.

To determine associations between OI and behavior (offline changes and D2-D1) in the DePo-M1 and DePo-FZ groups, we performed correlations using Spearman's $\rho$.

Statistical analyses were performed using SPSS (IBM). Effects were considered significant if $p \leq 0.05$. All data are given as means \pm SEM. 


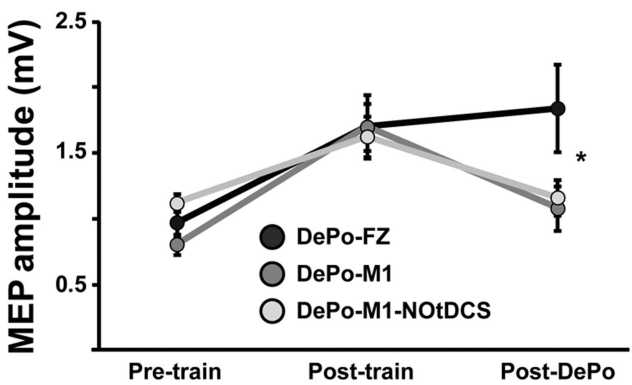

Figure 2. Corticospinal excitability changes for Pre-MT, Post-MT, and Post-DePo. y-Axis represents the MEP amplitudes in millivolts, and $x$-axis represents successive TMS measurements taken Pre-MT, immediately Post-MT, and again immediately Post-DePo. Black circles are the mean MEP amplitude for all DeP0-M1 subjects, dark gray circles are mean MEP amplitudes for all DeP0-FZ subjects, and light gray circles are mean MEP amplitudes for all DePo-M1NOtDCS subjects. After training, all groups showed a significant increase in MEP amplitude. However, after application of DePo over M1, subjects in groups DeP0-M1 and DePo-M1NOtDCS showed a decrease in mean MEP amplitude. In contrast, subjects in the DeP0-FZ group showed similar MEP amplitude before and after application of DePo over FZ. Data are means \pm SEM. ${ }^{*} p<0.05$.
In summary, motor learning induced an increase in corticospinal excitability, as described by an increase in mean MEP amplitude. DePo stimulation over M1 decreased the training-induced potentiation of corticospinal excitability, whereas DePo over control site FZ had no effect.

\section{Occlusion of LTP-like plasticity after motor skill learning}

The amount of potentiation plasticity aftereffects after AtDCS was compared between the groups DePo-M1 and DePo-FZ.

We found a significant effect on MEP amplitudes for day $(p<$ $0.01)$, time $(p<0.01)$, and day $\times$ group $(p=0.04)$ and day $\times$ time $(p=0.03)$ interactions . Before AtDCS (Pre-AtDCS measures), MEP amplitudes on D0 and D1 were not significantly different across groups (D0, $p=0.13$; D $1, p=0.14)$. After application of AtDCS on D0, MEPs in the DePo-FZ and DePo-M1 groups were significantly larger $(p<0.01, p<0.01$, respectively; Fig. 3). However, on D1, the same AtDCS protocol failed to increase MEPs when applied after training in the DePo-FZ group. Specifically, the mean MEP amplitudes after AtDCS in the baseline session (D0) were significantly larger than in the training session (D1) $(p=0.02)$. This indicates that skill training occluded AtDCS potentiating aftereffects. In contrast, DePo-M1 subjects showed similar increases in MEP amplitudes on both D0 and D1 after application of AtDCS (D0, pre-AtDCS vs post-AtDCS, $p<0.01$; D1, pre-AtDCS vs post-AtDCS $p=0.03$ ) but no difference in the amount of AtDCS aftereffects when comparing post-AtDCS effects across days ( $p=0.37$; Fig. 3 ). These results suggest that the occlusion of AtDCS-induced potentiation was specifically observed after learning, and this process was reversed after the application of DePo over M1.

Altogether, these results show that, after motor learning, subjects had a significant reduction of the typical enhancement of excitability expected from the application of AtDCS. This reduced facilitatory response to a stimulation protocol after learning has been characterized as occlusion of LTP in animal studies (RioultPedotti et al., 1998, 2007; Monfils and Teskey, 2004; Hodgson et al., 2005) and

Figure 3. MEP amplitude ratios for pre-AtDCS and post-AtDCS. $y$-Axis represents the average MEP amplitude standardized to the pre-AtDCS MEP amplitude, and $x$-axis represents successive TMS measurements taken before application of AtDCS (Pre), 列 subjects on D0 (baseline session). Gray circles are the mean MEP amplitude for all subjects on D1 (training session). Bar graphs depict the average MEP amplitude for 0,2 , and 4 min post-AtDCS for the baseline session (B) and for the training session (T). Left graph is MEP amplitudes for DeP0-FZ subjects, and right graph is MEP amplitudes for DeP0-M1 subjects. After motor training, DePo-FZ subjects showed a significant reduction of AtDCS-induced potentiating aftereffects compared with application after a period of rest (i.e., occlusion). In contrast, subjects who trained on the DeP0-M1 group showed similar amounts of AtDCS-induced potentiating plasticity either at rest or after training, demonstrating a lack of occlusion when DePo is applied over M1 after motor training. Data are means \pm SEM. ${ }^{*} p<0.05$.

\section{Results}

Corticospinal excitability changes after training and DePo

To assess changes in corticospinal excitability as a function of training and depotentiation, we assessed MEPs on D1 before training (Pre-MT), immediately after training (Post-MT), and immediately after application of DePo (Post-DePo) in the DePoFZ, DePo-M1, and DePo-M1-NOtDCS groups (Fig. 2).

Pre-MT MEP amplitudes were not significantly different $(p=$ $0.27)$. After training, all groups showed a similar significant increase in corticospinal excitability $(p<0.01)$. However, when we subtracted the Post-DePo from the Post-MT MEP amplitude to assess changes in excitability attributable to depotentiation, we found an effect for group $(p=0.05)$ in which subjects trained in either the DePo-M1 or DePo-M1-NOtDCS group showed a significant decrease in Post-DePo MEP amplitude relative to subjects in the DePo-FZ group ( $p=0.02, p=0.05$, respectively). Moreover, no significant differences were found between DePo-M1 and DePo-M1-NOtDCS ( $p=0.67)$. occlusion of LTP-like plasticity in humans (Ziemann et al., 2004; Stefan et al., 2006; Rosenkranz et al., 2007; Cantarero et al., 2013). Importantly, when we assessed excitability after training plus DePo over M1, the magnitude of AtDCS aftereffects was similar to D0, indicating that occlusion of LTP-like capacity was disrupted by DePo after learning of the skill task.

\section{Behavioral interference in motor skill learning}

To assess changes in the skill measure, we compared differences in performance across days and blocks in the DePo-FZ, DePoM1, and DePo-M1-NOtDCS groups.

We found a significant effect on the skill measure for day $(p<$ $0.01)$, epoch $(p<0.01)$, group $(p=0.05)$, and a day $\times$ group interaction $(p<0.01)$. All subjects started at a similar level of skill performance (no significant differences in performance across groups for the first epoch of training, $p=0.62$ ) and learned similar amounts on D1 $(p=0.90)$. However, subjects in the DePo-M1 and DePo-M1-NOtDCS groups experienced poorer 
A

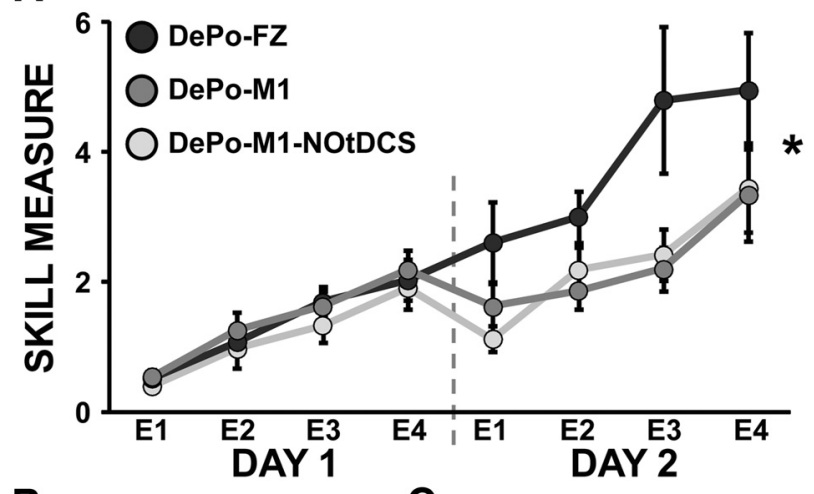

B

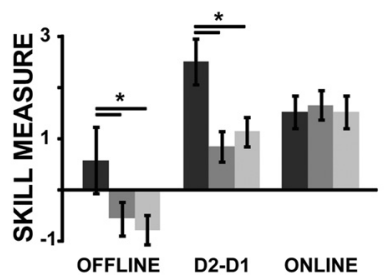

c

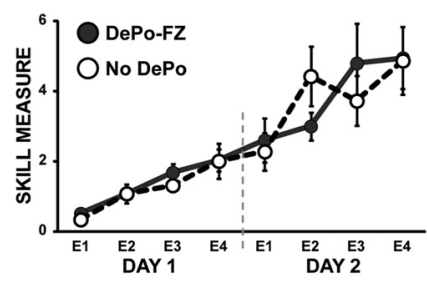

Figure 4. Performance on motor skill. Black circles are the average performances of the DeP0-FZ group, dark gray circles represent Group DeP0-M1, and light gray circles are the DeP0-M1-N0tDCS group. Vertical dotted line denotes the separation between D1 and D2 of training. $\boldsymbol{A}, y$-Axis represents the skill measure, and $x$-axis depicts epochs $(E)$ of training. Note that subjects who trained in the group DePo-FZ outperformed both DeP0-M1 groups (i.e., DeP0-M1 and DeP0-M1-N0tDCS) on D2 of training, whereas no significant differences in performance between groups were seen for D1. $\boldsymbol{B}$, The bar graphs show group averages for offline retention (left bar graph), D2 relative to D1 performance (D2-D1, middle bar graph), and online changes (right bar graph). Group DeP0-FZ was significantly better than groups DeP0-M1 and DeP0-M1-N0tDCS for D2-D1 and offline retention. However, all groups showed similar online changes for D1 of training. C, Black circles are the average performances of DePo-FZ group, and white circles are the No DePo group (data originally presented by Cantarero et al., 2013). No significant differences were present between subjects who trained with or without DePo over FZ. Data are means \pm SEM. ${ }^{*} p<0.05$.

performance on the second day of practice compared with subjects who trained in the DePo-FZ $(p=0.03, p=0.03$, respectively; Fig. 4A). Moreover, whereas online (within-day) learning was not different between groups for either D1 or D2, offline changes and performance on D2 relative to D1 (D2-D1) were significantly better in the DePo-FZ group relative to the DePo-M1 (offline changes, $p=0.03$; D2-D1, $p<0.01$ ) and DePo-M1NOtDCS (offline changes, $p=0.01$; D2-D1, $p=0.01$; Fig. $4 B$ ) groups. These results indicate that DePo immediately after skill training disrupted retention on D2. There were no significant differences in behavior found between subjects in the DePo-M1 and DePo-M1-NOtDCS groups, indicating that AtDCS applied after skill training did not affect performance or the effects of depotentiation.

It is possible that application of DePo over FZ could have affected motor performance. To address this, we performed an additional analysis and comparison using previously published data (Cantarero et al., 2013). Here we compared motor performance in DePo-FZ and No DePo groups and found no significant differences between groups, indicating that application of DePo over FZ did not affect motor performance (Fig. 4C).

Behavioral-physiological correlation of motor skill learning In previous work, we found that larger occlusion effects (suggestive of more LTP-like plasticity resources used) after learning is

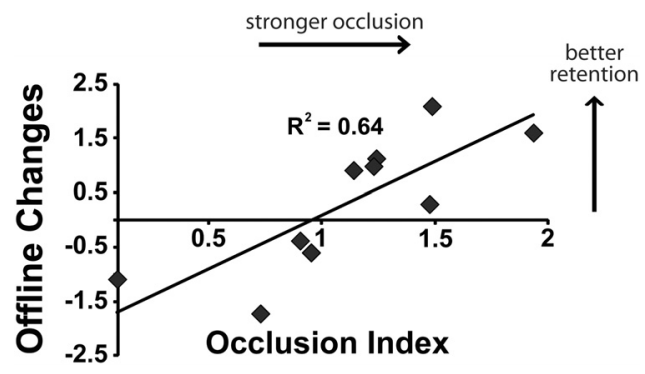

Figure 5. Correlation between occlusion of LTP-like plasticity and behavior. $y$-Axis represents offline changes, and the $x$-axis represents the 0 . Black diamonds represent individual subjects of group DeP0-FZ. Note that subjects who had the largest 0 l after training had the best retention, whereas subjects who had the smallest 0 lafter training showed the poorest retention.

associated with better performance of the skill the following day. We performed a correlation between physiological changes (OI) and behavior (offline changes and D2-D1) in all subjects. We found a significant correlation between $\mathrm{OI}$ and offline changes $\left(R^{2}=0.64, p<0.01\right)$ for subjects in the DePo-FZ group (Fig. 5). In addition, we also found a significant correlation between the OI and the skill performance difference between practice days (D2-D1, $\left.R^{2}=0.5, p<0.01\right)$. These results replicate previous findings indicating an association between occlusion of AtDCS aftereffects and skill retention (Cantarero et al., 2013).

\section{Discussion}

The main findings of this study include the following: (1) DePo reduces learning-induced potentiation; (2) depotentiation disrupts the occlusion of LTP-like plasticity observed after learning; (3) depotentiation applied after training impairs retention of motor skill learning; and (4) the magnitude of occlusion after motor training correlated positively with retention as determined by offline changes and D2-D1 performance. Importantly, we also showed in our DePo-M1-NOtDCS control group that AtDCS applied after skill training did not affect the interaction between training and DePo. Finally, a separate control group (No DePo) behaved similarly to DePo-FZ, suggesting that DePo over FZ did not affect motor training or retention.

Changes in the strength of synaptic connections are widely believed to play a role in learning and memory (Martin et al., 2000). In both animals and humans, motor learning induces an increase in motor cortical excitability (Rioult-Pedotti et al., 1998; Monfils and Teskey, 2004; Hodgson et al., 2005) that is blocked with NMDA receptor antagonists (Martin and Morris, 2001). Consistent with these studies, we found that training on the SVIPT led to an increase in corticospinal excitability. In addition, evidence in animals that learning and memory engage LTP mechanisms in M1 stems from the finding that motor learning is also associated with occlusion of LTP, i.e., a reduced capacity to electrically induce LTP (Rioult-Pedotti et al., 1998, 2000, 2007). A principle property of LTP and LTD induction are that they saturate. In other words, the motor cortex has a finite capacity for artificially modulating motor cortical plasticity, termed the synaptic modification range (Rioult-Pedotti et al., 1998, 2000, 2007). Thus, if motor skill learning uses up some of the plasticity available at motor cortical synapses, then additional strengthening of motor cortical synapses through LTP-like mechanisms should be blocked or occluded. Evidence of this phenomenon of occlusion of LTP in animals (Rioult-Pedotti et al., 1998, 2000, 2007) has also been demonstrated in humans using non-invasive brain stimulation (Ziemann et al., 2004; Stefan et al., 2006; Rosenkranz 
et al., 2007; Cantarero et al., 2013) and is consistent with the current study, again suggesting that motor training engages an LTP-like mechanism to strengthen synapses.

The motor cortex has been implicated to play a fundamental role in retention of motor learning (Muellbacher et al., 2002; Robertson et al., 2004, 2005; Cothros et al., 2006; Richardson et al., 2006; Hadipour-Niktarash et al., 2007; Korman et al., 2007; Reis et al., 2009; Galea et al., 2011). Thus, we argue that LTP processes resulting in occlusion of additional LTP-like plasticity in M1 might be one of the mechanisms fundamental for retention. Here we applied DePo over M1, which resulted in reduced learning-dependent potentiation and disrupted occlusion of LTP-like plasticity. Note that the disruption of occlusion was demonstrated as artificially restoring the capacity for AtDCS to induce LTP-like plasticity, even after motor training. Importantly, this reversal of occlusion was associated with impairment of skill retention. This is not only compatible with the properties of the reversibility of LTP but also suggests that, if synapses are moved back toward the midpoint of the synaptic modification range (i.e., so that additional strengthening of synapses through LTP-like mechanisms is possible), it affects the mechanisms supporting retention.

It is possible that, although occlusion of LTP-like plasticity is essential for retention, it may also play a role for acquisition of learning. Although the current study was not designed to test this directly, we did find that the magnitude of occlusion of LTP plasticity correlated with offline changes, as well as with overall performance of the motor task on D2 but did not correlate significantly with acquisition during the first day of training. Thus, our findings would suggest that occlusion plays a critical role in retention rather than acquisition of motor learning. This finding is consistent with other studies suggesting that blocking of protein synthesis (McGaugh, 2000) and/or application of enhancive or disruptive stimulation over M1 affects retention without affecting acquisition of motor learning (Muellbacher et al., 2002; Robertson et al., 2004, 2005; Cothros et al., 2006; Richardson et al., 2006; Hadipour-Niktarash et al., 2007; Korman et al., 2007; Galea et al., 2011).

Importantly, it is unlikely that use of AtDCS to quantify the magnitude of occlusion of LTP-like plasticity could have affected behavioral performance. Indeed, we found that DePo-M1-NOtDCS control group had similar motor performance to those who received AtDCS, DePo-M1. This is consistent with previous work showing that application of AtDCS over M1 after training does not affect behavior (Fritsch et al., 2010; Cantarero et al., 2013). Moreover, it is possible that DePo over FZ may influence surrounding motor areas known to be involved in motor learning, such as the supplementary motor area and premotor cortex. However, this was not the case because a direct comparison between the DePo-FZ and the No DePo groups did not show a difference in motor learning. This finding indicates that DePo applied over FZ did not affect motor performance of our task.

Our study shows that depotentiation is capable of impairing performance. This is an interesting and subtle technique considering that depotentiation alone has no effect on corticospinal M1 excitability (Huang et al., 2010). Importantly, animal studies in reduced preparations have shown that depotentiation engages distinct cellular mechanisms compared with LTD and that depotentiation is not simply a summation of LTP and LTD (Zhou and Poo, 2004). For instance, it has been shown that some forms of depotentiation may activate protein phosphatase- 1 and phosphatase-A and reverse the phosphorylation of Ser831 on the GluR1 subunit of the AMPA receptor caused by LTP induction, thereby stopping ongoing LTP (Huang et al., 2001). In contrast, the Ser845 on GluR1, which is dephosphorylated to produce
LTD, is unaffected during depotentiation (Zhou and Poo, 2004). Thus, depotentiation protocols have been suggested to specifically reverse LTP-like induction by targeting synapses that were recently potentiated (Lee et al., 2000). For this reason, depotentiation in humans can be helpful to probe the presence of LTP plasticity mechanisms. However, one limitation of the present interpretation is that, because the work exploring the underlying mechanism of depotentiation is based on animal studies, whether DePo in humans is dependent on the exact same mechanism in humans cannot be made with absolute certainty.

An alternative explanation may be that the disruptive effects of DePo applied over M1 on physiology and retention was simply attributable to the application of "noise" after the motor training. However, evidence in both our current study and previous work (Reis et al., 2009; Fritsch et al., 2010; Cantarero et al., 2013) has shown that application of tDCS over M1 after motor training does not affect motor performance. This would suggest that application of any type of noise (i.e., tDCS) is not sufficient to disrupt performance. Similarly, the assessment of corticomotor excitability commonly done with single or paired-pulse TMS before and after motor training does not typically result in differences in motor behavior. Thus, the lack of behavioral effects by these forms of stimulation eliciting some type of noise, together with the consequences of DePo in humans (Huang et al., 2010, 2011) and in animals (Lee et al., 2000; Huang et al., 2001; Zhou and Poo, 2004), support the idea that the DePo protocol has a specific effect on depotentiation.

Depotentiation affords some advantages over the usage of other repetitive TMS (rTMS) protocols. First, unlike depotentiation $1 \mathrm{~Hz}$ rTMS applied during rest has been shown to elicit cortical inhibition (Chen et al., 1997; Gangitano et al., 2002; Romero et al., 2002) as well as widespread, nonsynaptic specific motor cortex excitability changes (Ziemann et al., 1998; Trippe et al., 2009). Second, rTMS elicits longer lasting changes in short intracortical inhibition (SICI) than in MEP amplitude (Wu et al., 2000); moreover, application of dextromethorphan (NMDA receptor antagonist) only blocks rTMS changes in SICI but not MEP amplitudes (Ziemann et al., 1998). Collectively, these studies suggest that rTMS changes in MEP amplitude may be driven by changes in cortical inhibition. Finally, aftereffects elicited with rTMS can engage metaplasticity mechanisms known to prevent the neuronal system from moving to instability by reversing LTP/ LTD induction rather than abolishing it. These mechanisms have also been implicated in modifying NMDA receptors, NMDARmediated calcium influx (Abraham, 2008), and activity of some types of potassium channel (Surmeier and Foehring, 2004).

Altogether, our results suggest that LTP-like plasticity in M1, as reflected by occlusion, is at least one of the mechanisms underlying skill retention. Motor-learning induced LTP-like plasticity after training is essential for performance the following day; reversal (i.e., depotentiation) of these LTP-like aftereffects impairs retention. Our results also suggest that determining the magnitude of occlusion after motor training could be used as a biomarker for the magnitude of motor learning retention. Importantly, the findings of this study indicate that attempts to reverse the occlusion of LTP-like plasticity after motor learning, for instance to reestablish learning capacity, may come with the cost of reducing retention of motor learning.

\section{References}

Abraham WC (2008) Metaplasticity: tuning synapses and networks for plasticity. Nat Rev Neurosci 9:387. CrossRef Medline

Block H, Bastian A, Celnik P (2013) Virtual lesion of angular gyrus disrupts 
the relationship between visuoproprioceptive weighting and realignment. J Cogn Neurosci 25:636-648. CrossRef Medline

Bock O, Schneider S, Bloomberg J (2001) Conditions for interference versus facilitation during sequential sensorimotor adaptation. Exp Brain Res 138:359-365. CrossRef Medline

Brashers-Krug T, Shadmehr R, Bizzi E (1996) Consolidation in human motor memory. Nature 382:252-255. CrossRef Medline

Cantarero G, Tang B, O’Malley R, Salas R, Celnik P (2013) Motor learning interference is proportional to occlusion of LTP-like plasticity. J Neurosci 33:4634-4641. CrossRef Medline

Chen R, Classen J, Gerloff C, Celnik P, Wassermann EM, Hallett M, Cohen LG (1997) Depression of motor cortex excitability by low-frequency transcranial magnetic stimulation. Neurology 48:1398-1403. CrossRef Medline

Cohen LG, Celnik P, Pascual-Leone A, Corwell B, Falz L, Dambrosia J, Honda M, Sadato N, Gerloff C, Catalá MD, Hallett M (1997) Functional relevance of cross-modal plasticity in blind humans. Nature 389:180-183. CrossRef Medline

Conner JM, Culberson A, Packowski C, Chiba AA, Tuszynski MH (2003) Lesions of the basal forebrain cholinergic system impair task acquisition and abolish cortical plasticity associated with motor skill learning. Neuron 38:819-829. CrossRef Medline

Cothros N, Köhler S, Dickie EW, Mirsattari SM, Gribble PL (2006) Proactive interference as a result of persisting neural representations of previously learned motor skills in primary motor cortex. J Cogn Neurosci 18:2167-2176. CrossRef Medline

Criscimagna-Hemminger SE, Shadmehr R (2008) Consolidation patterns of human motor memory. J Neurosci 28:9610-9618. CrossRef Medline

Fritsch B, Reis J, Martinowich K, Schambra HM, Ji Y, Cohen LG, Lu B (2010) Direct current stimulation promotes BDNF-dependent synaptic plasticity: potential implications for motor learning. Neuron 66:198-204. CrossRef Medline

Galea JM, Vazquez A, Pasricha N, de Xivry JJ, Celnik P (2011) Dissociating the roles of the cerebellum and motor cortex during adaptive learning: the motor cortex retains what the cerebellum learns. Cereb Cortex 21:1761-1770. CrossRef Medline

Gangitano M, Valero-Cabré A, Tormos JM, Mottaghy FM, Romero JR, Pascual-Leone A (2002) Modulation of input-output curves by low and high frequency repetitive transcranial magnetic stimulation of the motor cortex. Clin Neurophysiol 113:1249-1257. CrossRef Medline

Ghilardi MF, Moisello C, Silvestri G, Ghez C, Krakauer JW (2009) Learning of a sequential motor skill comprises explicit and implicit components that consolidate differently. J Neurophysiol 101:2218-2229. CrossRef Medline

Goedert KM, Willingham DB (2002) Patterns of interference in sequence learning and prism adaptation inconsistent with the consolidation hypothesis. Learn Mem 9:279-292. CrossRef Medline

Hadipour-Niktarash A, Lee CK, Desmond JE, Shadmehr R (2007) Impairment of retention but not acquisition of a visuomotor skill through time-dependent disruption of primary motor cortex. J Neurosci 27:13413-13419. CrossRef Medline

Hodgson RA, Ji Z, Standish S, Boyd-Hodgson TE, Henderson AK, Racine RJ (2005) Training-induced and electrically induced potentiation in the neocortex. Neurobiol Learn Mem 83:22-32. CrossRef Medline

Huang CC, Liang YC, Hsu KS (2001) Characterization of the mechanism underlying the reversal of long term potentiation by low frequency stimulation at hippocampal CA1 synapses. J Biol Chem 276:48108-48117. CrossRef Medline

Huang YZ, Rothwell JC, Lu CS, Chuang WL, Lin WY, Chen RS (2010) Reversal of plasticity-like effects in the human motor cortex. J Physiol 588: 3683-3693. CrossRef Medline

Huang YZ, Rothwell JC, Lu CS, Chuang WL, Chen RS (2011) Abnormal bidirectional plasticity-like effects in Parkinson's disease. Brain 134: 2312-2320. CrossRef Medline

Islam N, Aftabuddin M, Moriwaki A, Hattori Y, Hori Y (1995) Increase in the calcium level following anodal polarization in the rat brain. Brain Res 684:206-208. CrossRef Medline

Kleim JA, Barbay S, Nudo RJ (1998) Functional reorganization of the rat motor cortex following motor skill learning. J Neurophysiol 80: 3321-3325. Medline

Kleim JA, Barbay S, Cooper NR, Hogg TM, Reidel CN, Remple MS, Nudo RJ (2002) Motor learning-dependent synaptogenesis is localized to func- tionally reorganized motor cortex. Neurobiol Learn Mem 77:63-77. CrossRef Medline

Kleim JA, Bruneau R, Calder K, Pocock D, VandenBerg PM, MacDonald E, Monfils MH, Sutherland RJ, Nader K (2003) Functional organization of adult motor cortex is dependent upon continued protein synthesis. Neuron 40:167-176. CrossRef Medline

Korman M, Doyon J, Doljansky J, Carrier J, Dagan Y, Karni A (2007) Daytime sleep condenses the time course of motor memory consolidation. Nat Neurosci 10:1206-1213. CrossRef Medline

Krakauer JW, Shadmehr R (2006) Consolidation of motor memory. Trends Neurosci 29:58-64. CrossRef Medline

Krakauer JW, Ghez C, Ghilardi MF (2005) Adaptation to visuomotor transformations: consolidation, interference, and forgetting. J Neurosci 25: 473-478. CrossRef Medline

Lagerlund TD, Sharbrough FW, Jack CR Jr, Erickson BJ, Strelow DC, Cicora KM, Busacker NE (1993) Determination of 10-20 system electrode locations using magnetic resonance image scanning with markers. Electroencephalogr Clin Neurophysiol 86:7-14. CrossRef Medline

Lee HK, Barbarosie M, Kameyama K, Bear MF, Huganir RL (2000) Regulation of distinct AMPA receptor phosphorylation sites during bidirectional synaptic plasticity. Nature 405:955-959. CrossRef Medline

Liebetanz D, Nitsche MA, Tergau F, Paulus W (2002) Pharmacological approach to the mechanisms of transcranial DC-stimulation-induced aftereffects of human motor cortex excitability. Brain 125:2238-2247. CrossRef Medline

Liepert J, Classen J, Cohen LG, Hallett M (1998) Task-dependent changes of intracortical inhibition. Exp Brain Res 118:421-426. CrossRef Medline

Martin SJ, Morris RG (2001) Cortical plasticity: it's all the range! Curr Biol 11:R57-R59. CrossRef

Martin SJ, Grimwood PD, Morris RG (2000) Synaptic plasticity and memory: an evaluation of the hypothesis. Annu Rev Neurosci 23:649-711. CrossRef Medline

McGaugh JL (2000) Memory-a century of consolidation. Science 287: 248-251. CrossRef Medline

Monfils MH, Teskey GC (2004) Skilled-learning-induced potentiation in rat sensorimotor cortex: a transient form of behavioural long-term potentiation. Neuroscience 125:329-336. CrossRef Medline

Muellbacher W, Ziemann U, Boroojerdi B, Cohen L, Hallett M (2001) Role of the human motor cortex in rapid motor learning. Exp Brain Res 136: 431-438. CrossRef Medline

Muellbacher W, Ziemann U, Wissel J, Dang N, Kofler M, Facchini S, Boroojerdi B, Poewe W, Hallett M (2002) Early consolidation in human primary motor cortex. Nature 415:640-644. CrossRef Medline

Nitsche MA, Fricke K, Henschke U, Schlitterlau A, Liebetanz D, Lang N, Henning S, Tergau F, Paulus W (2003) Pharmacological modulation of cortical excitability shifts induced by transcranial direct current stimulation in humans. J Physiol 553:293-301. CrossRef Medline

Nudo RJ, Milliken GW, Jenkins WM, Merzenich MM (1996) Usedependent alterations of movement representations in primary motor cortex of adult squirrel monkeys. J Neurosci 16:785-807. Medline

Perez MA, Lungholt BK, Nyborg K, Nielsen JB (2004) Motor skill training induces changes in the excitability of the leg cortical area in healthy humans. Exp Brain Res 159:197-205. CrossRef Medline

Ranieri F, Podda MV, Riccardi E, Frisullo G, Dileone M, Profice P, Pilato F, Di Lazzaro V, Grassi C (2012) Modulation of LTP at rat hippocampal CA3CA1 synapses by direct current stimulation. J Neurophysiol 107:18681880. CrossRef Medline

Reis J, Schambra HM, Cohen LG, Buch ER, Fritsch B, Zarahn E, Celnik PA, Krakauer JW (2009) Noninvasive cortical stimulation enhances motor skill acquisition over multiple days through an effect on consolidation. Proc Natl Acad Sci U S A 106:1590-1595. CrossRef Medline

Remple MS, Bruneau RM, VandenBerg PM, Goertzen C, Kleim JA (2001) Sensitivity of cortical movement representations to motor experience: evidence that skill learning but not strength training induces cortical reorganization. Behav Brain Res 123:133-141. CrossRef Medline

Richardson AG, Overduin SA, Valero-Cabré A, Padoa-Schioppa C, PascualLeone A, Bizzi E, Press DZ (2006) Disruption of primary motor cortex before learning impairs memory of movement dynamics. J Neurosci 26: 12466-12470. CrossRef Medline

Rioult-Pedotti MS, Friedman D, Hess G, Donoghue JP (1998) Strengthening of horizontal cortical connections following skill learning. Nat Neurosci 1:230-234. CrossRef Medline 
Rioult-Pedotti MS, Friedman D, Donoghue JP (2000) Learning-Induced LTP in Neocortex. Science 290:533-536. CrossRef Medline

Rioult-Pedotti MS, Donoghue JP, Dunaevsky A (2007) Plasticity of the synaptic modification range. J Neurophysiol 98:3688-3695. CrossRef Medline

Robertson EM, Pascual-Leone A, Miall RC (2004) Current concepts in procedural consolidation. Nat Rev Neurosci 5:576-582. CrossRef Medline

Robertson EM, Press DZ, Pascual-Leone A (2005) Off-line learning and the primary motor cortex. J Neurosci 25:6372-6378. CrossRef Medline

Romero JR, Anschel D, Sparing R, Gangitano M, Pascual-Leone A (2002) Subthreshold low frequency repetitive transcranial magnetic stimulation selectively decreases facilitation in the motor cortex. Clin Neurophysiol 113:101-107. CrossRef Medline

Rosenkranz K, Kacar A, Rothwell JC (2007) Differential modulation of motor cortical plasticity and excitability in early and late phases of human motor learning. J Neurosci 27:12058-12066. CrossRef Medline

Rossini PM, Barker AT, Berardelli A, Caramia MD, Caruso G, Cracco RQ, Dimitrijeviç MR, Hallett M, Katayama Y, Lücking CH (1994) Noninvasive electrical and magnetic stimulation of the brain, spinal cord and roots: basic principles and procedures for routine clinical application: report of an IFCN committee. Electroencephalogr Clin Neurophysiol 91: 79-92. CrossRef Medline

Sanes JN, Donoghue JP (2000) Plasticity and primary motor cortex. Annu Rev Neurosci 23:393-415. CrossRef Medline

Shadmehr R, Brashers-Krug T (1997) Functional stages in the formation of human long-term motor memory. J Neurosci 17:409-419. Medline

Stagg CJ, Best JG, Stephenson MC, O'Shea J, Wylezinska M, Kincses ZT, Morris PG, Matthews PM, Johansen-Berg H (2009) Polarity-sensitive modulation of cortical neurotransmitters by transcranial stimulation. J Neurosci 29:5202-5206. CrossRef Medline
Stefan K, Wycislo M, Gentner R, Schramm A, Naumann M, Reiners K, Classen J (2006) Temporary occlusion of associative motor cortical plasticity by prior dynamic motor training. Cereb Cortex 16:376-385. CrossRef Medline

Surmeier DJ, Foehring R (2004) A mechanism for homeostatic plasticity. Nat Neurosci 7:691-692. CrossRef Medline

Trippe J, Mix A, Aydin-Abidin S, Funke K, Benali A (2009) $\theta$ burst and conventional low-frequency rTMS differentially affect GABAergic neurotransmission in the rat cortex. Exp Brain Res 199:411-421. CrossRef Medline

Walker MP, Brakefield T, Hobson JA, Stickgold R (2003) Dissociable stages of human memory consolidation and reconsolidation. Nature 425:616-620. CrossRef Medline

Wigmore V, Tong C, Flanagan JR (2002) Visuomotor rotations of varying size and direction compete for a single internal model in motor working memory. J Exp Psychol Hum Percept Perform 28:447-457. CrossRef Medline

Wu T, Sommer M, Tergau F, Paulus W (2000) Lasting influence of repetitive transcranial magnetic stimulation on intracortical excitability in human subjects. Neurosci Lett 287:37-40. CrossRef Medline

Zhou Q, Poo MM (2004) Reversal and consolidation of activity-induced synaptic modifications. Trends Neurosci 27:378-383. CrossRef Medline

Ziemann U, Corwell B, Cohen LG (1998) Modulation of plasticity in human motor cortex after forearm ischemic nerve block. J Neurosci 18: 1115-1123. Medline

Ziemann U, Iliać TV, Pauli C, Meintzschel F, Ruge D (2004) Learning modifies subsequent induction of long-term potentiation-like and long-term depression-like plasticity in human motor cortex. J Neurosci [Erratum (2004) 24:1 p following 10552, Iliać, Tihomir V (corrected to Ilić, Tihomir V)] 24:1666-1672. CrossRef Medline 